\title{
ENFERMAGEM DE REABILITAÇÃO NO BRASIL FRENTE À SITUAÇÃO DE PANDEMIA: ESTUdO DE CASO
}

\section{ENFERMERÍA DE REHABILITACIÓN EN BRASIL DELANTE DE LA SITUACIÓN DE LA PANDEMIA: ESTUDIO DE CASO}

\author{
REHABILITATION NURSING IN BRAZIL IN FRONT OF THE SITUATION OF PANDEMIC: CASE STUDY
}

DOI 10.33194/rper.2020.v3.s2.7.5795 | Submetido 10/06/2020 | Aprovado 15/11/2020

\author{
Milena Amorim Zuchetto ${ }^{1} \mathbb{D}$; André Roberto Faria ${ }^{2} \mathbb{D}$; Kátrin Aline Osti ${ }^{3} \mathbb{D}$; Luciana Schroeder ${ }^{3} \mathbb{D}$; \\ Maria Madalena Santiago ${ }^{4}\left(\mathbb{D}\right.$; Soraia Dornelles Schoeller ${ }^{1}(\mathbb{D})$ \\ 1 - Universidade Federal de Santa Catarina; 2 - Universidade do Planalto Catarinense; 3 - Universidade Regional de Blumenau; \\ 4 - Universidade do Extremo Sul Catarinense
}

\section{RESUMO}

A enfermagem de reabilitação no Brasil é estabelecida, prioritariamente, dentro de Centro Especializados de Reabilitação, onde enfermeiros desenvolvem ações de cuidado para alcançar o potencial máximo de saúde do usuário. Nesse contexto, o cenário de pandemia provoca múltiplas alterações no processo de cuidar, influenciando novas maneiras de pensar o trabalho do enfermeiro. Logo, o estudo objetiva compreender como os enfermeiros de reabilitação estão vivenciando o cenário de pandemia mundial, respondendo à questão "Como está a realidade da enfermagem de reabilitação no estado de Santa Catarina - Brasil frente ao cenário de pandemia?". Para isso a pesquisa possui abordagem qualitativa, delineada pelo método de estudos de casos múltiplos, evidenciando a realidade de cinco enfermeiros de reabilitação em quatro centros de reabilitação do estado de Santa Catarina. A partir dos dados emergiram três categorias, as quais descrevem como foram os preparos para o fechamento dos serviços, como a enfermagem se reinventou em tempos de pandemia, quais foram os desafios e potencialidades encontradas nessa trajetória e o que se espera do futuro. Conclui-se que diante às mudanças vivenciadas pelos enfermeiros de reabilitação, cada instituição assumiu um posicionamento que impactou diretamente o processo de trabalho dos enfermeiros, sendo necessário reinventar a forma de cuidar e criar mecanismos para compartilhar medidas de prevenção em meio ao isolamento social.

Palavras-chave: enfermagem de reabilitação; mídias sociais; pandemias

\section{RESUMEN}

La enfermería de rehabilitación en Brasil se establece, principalmente, dentro del Centro de Rehabilitación Especializada, donde las enfermeras desarrollan acciones de atención para alcanzar el máximo potencial de salud del usuario. En este contexto, el escenario de la pandemia provoca múltiples cambios en el proceso de atención, influyendo en nuevas formas de pensar sobre el trabajo de la enfermera en este contexto. Por lo tanto, el estudio tiene como objetivo comprender cómo las enfermeras de rehabilitación están experimentando el escenario de la pandemia mundial respondiendo a la pregunta "¿Cómo se enfrenta la realidad de la enfermería rehabilitadora en el estado de Santa Catarina - Brasil al escenario pandémico?". Para esto, la investigación tiene un enfoque cualitativo, delineado por el método de estudios de casos múltiples, que muestra la realidad de cinco enfermeras de rehabilitación en cuatro centros de rehabilitación en el estado de Santa Catarina. A partir de los datos, surgieron tres categorías, que describen cómo se hicieron los preparativos para el cierre de los servicios, cómo la enfermería se reinventó en tiempos de pandemia, cuáles fueron los desafíos y el potencial encontrados en esta trayectoria y qué se espera del futuro. Se concluye que en vista de los cambios experimentados por las enfermeras de rehabilitación, cada institución asumió una posición que impactó directamente el proceso de trabajo de las enfermeras, siendo necesario reinventar la forma de cuidar y crear mecanismos para compartir medidas preventivas en medio del aislamiento social.

Palabras clave: enfermería de rehabilitación; medios de comunicación sociales; pandemias

\section{ABSTRACT}

Rehabilitation nursing in Brazil is established, primarily, within the Specialized Rehabilitation Center, where nurses develop care actions to reach the maximum health potential of the user. In this context, the pandemic scenario causes multiple changes in the care process, influencing new ways of thinking about the nurse's work in this context. Therefore, the study aims to understand how rehabilitation nurses are experiencing the world pandemic scenario, answering the question "How is the reality of rehabilitation nursing in the state of Santa Catarina - Brazil facing the pandemic scenario?". For this, the research has a qualitative approach, outlined by the method of multiple case studies, showing the reality of five rehabilitation nurses in four rehabilitation centers in the state of Santa Catarina. From the data, three categories emerged, which describe how the preparations were made for the closure of services, how nursing reinvented itself in times of pandemic, what were the challenges and potential found in this trajectory and what is expected of the future. It is concluded that in view of the changes experienced by the rehabilitation 
nurses, each institution assumed a position that directly impacted the nurses' work process, being necessary to reinvent the way of caring and create mechanisms to share preventive measures in the midst of social isolation.

Keywords: rehabilitation nursing; social media; pandemics

\section{INTRODUÇÃO}

A enfermagem de reabilitação é uma especialidade que apresenta como finalidade as ações de cuidado que impulsionem o alcance do potencial máximo de saúde do usuário. Para desenvolver essa tarefa, o enfermeiro de reabilitação deve considerar as barreiras que influenciam a acessibilidade, a participação social e o exercício pleno da cidadania(1). Essas intervenções requerem do enfermeiro de reabilitação a incorporação de boas práticas baseadas em evidências científicas, assim como a construção de um cuidado centrado na pessoa em reabilitação, identificando situações de preconceito, e buscando envolver os recursos pessoais, familiares, domiciliares e comunitários no processo de cuidado $^{(2)}$.

Porém, mesmo diante da relevância da especialidade, ela é incipiente no contexto brasileiro, não sendo reconhecida, ao menos, como especialidade de enfermagem. Esse contexto desvaloriza o profissional que atua nesse cenário de saúde em nível nacional e fragiliza a produção científica na área(3). Mesmo assim, a Política Nacional de Saúde à Pessoa com Deficiência foi instituída em 2002, por meio da portaria $n^{\circ} 1.060$, visa incluir as pessoas com deficiência na rede de serviços do Sistema Único de Saúde (SUS), sendo que um dos pontos dessa Rede é o Centro Especializado de Reabilitação (CER), compreendendo um serviço ambulatorial especializado que realiza diagnóstico, tratamento, concessão, adaptação e manutenção de tecnologia assistiva, organizado por tipo de deficiência, podendo envolver: deficiência auditiva, visual, intelectual ou física(4). No estado de Santa Catarina existem cinco CER habilitados pelo Ministério da Saúde, compreendendo a demanda da macrorregião da grande Florianópolis, regiões Carboníferas e Extremo Sul, a macrorregião da Foz do Itajaí, a macrorregião da Serra Catarinense e região da saúde do médio Vale do Itajaí. Esses CERs são, em sua totalidade, do Tipo II com especialidade no atendimento à pessoa com deficiência intelectual ou física ${ }^{(5)}$.

Mesmo diante da construção histórica que impulsiona os cuidados de enfermagem de reabilitação a restringirem-se aos muros dos CER ${ }^{(1)}$, os esforços dos enfermeiros de reabilitação nos últimos anos favorecem a ampliação desse em saúde. Porém, o ano de 2020 surpreendeu a todos com a situação de crise mundial causada pelo cenário pandêmico, causando modificações nas formas de estabelecer as relações humanas, especialmente, pelo distanciamento, isolamento social, medo, incertezas e frustrações vivenciadas. Dessa maneira, são diversas as razões para repensar o cuidado de enfermagem de reabilitação que se realiza em meio ao atual cenário, considerando que essa profissão é, historicamente, vinculada à presença e toque terapêutico ${ }^{(6)}$.

Diante disso, é fato que o cenário de pandemia gerou impactos no cuidado de enfermagem, mas ainda se desconhece como a enfermagem de reabilitação tem lidado com essas novas circunstâncias no cenário brasileiro. Logo, o estudo busca compreender como os enfermeiros de CER do estado de Santa Catarina estão vivenciando o cenário de pandemia mundial, considerando que as intervenções presenciais foram modificadas pelo cenário de isolamento social.

\section{MÉTODO}

Estudo de abordagem qualitativa, com estratégia metodológica de Estudo de Casos Múltiplos. O estudo de caso é um método de pesquisa estruturado, o qual se preocupa em solucionar questões de pesquisa que ressaltam o "como" e o "porquê" de fenômenos individuais e grupais ${ }^{(7)}$. 0 estudo de caso é formado por cinco componentes essenciais: questão de estudo; proposição(ões); unidade de análise; lógica que irá unir os dados às proposições; e os critérios para interpretar as constatações ${ }^{(8)}$.

Contextualizando a pesquisa, o presente estudo foi desenvolvido em todos os CERs do estado de Santa Catarina, mais especificamente, nos municípios de Florianópolis, Criciúma, Lages, Itajaí e Blumenau. Os participantes do estudo envolvem enfermeiros de reabilitação com tempo de experiência no CER de mais de 12 meses. 0 critério de exclusão envolvia enfermeiros de reabilitação que apresentassem atividades unicamente de gestão da instituição. Diante desses critérios, o CER do município de Itajaí foi excluído do estudo por não apresentar enfermeiro de reabilitação lotado no momento da coleta de dados. Os demais enfermeiros dos CER foram incluídos, consistindo na amostra total de cinco participantes.

Vale ressaltar que o foco central dessa pesquisa é responder a seguinte questão: Como está a realidade da enfermagem de reabilitação no estado de Santa Catarina - Brasil frente ao cenário de pandemia? Por isso, a técnica de coleta de dados escolhida para compreender esse fenômeno foi a Observação Participante e os Relatos de vivências dos pesquisadores na prática assistencial nos CERs em tempos de pandemia. Dessa maneira, foram registadas Notas de Observação (NO) e Áudios descritivos para elaborar categorizações das vivências de enfermeiros de reabilitação de cada realidade enfrentada na situação de isolamento social, encontrando as convergências e divergências de cada contexto. Vale ressaltar que essa pesquisa faz parte de um macroprojeto intitulado "Cuidado de enfermagem de reabilitação como processo emancipatório", aprovado conforme CAEE $\mathrm{n}^{\circ}$ 02022918.5.0000.0121 e Parecer $\mathrm{n}^{\circ}$ 3.094.742, sendo os participantes chamados de Enf (enfermeiros) e número sequencial.

Enquanto quatro pesquisadores estavam imersos nas realidades dos CERs para realizar os registros de NO, outros dois pesquisadores agregavam os relatos 
gravados em áudios e leituras de NO para a análise conjunta dos dados obtidos. Isto posto, a lógica de união dos dados é apresentada a partir das vivências, por meio de uma síntese cruzada de categoria e subcategorias relativas aos temas que emergiram, resultando na classificação progressiva dos elementos da pesquisa. Para organização dos dados qualitativos, utilizou-se o software Excel, sendo analisados à luz da Análise de Conteúdo( ${ }^{(9)}$, visando atingir o rigor metodológico e compreensão profunda dos dados. $\mathrm{Na}$ etapa final, evidenciaram-se três categorias principais: O choque de uma crise mundial - chegou na nossa realidade; $O$ enfrentamento da pandemia com as portas fechadas; e 0 que será do futuro?

\section{RESULTADOS E DISCUSSÃO}

\section{Perfil da amostra e síntese dos achados}

Dos cinco enfermeiros de reabilitação participantes, um era do sexo masculino e quatro do sexo feminino, com faixa etária entre 25 e 50 anos de idade. Todos possuíam graduação em Enfermagem, com variação de três a 17 anos de formados e com tempo de atuação no CER de um a quatro anos. Quanto aos cursos de pósgraduação, três possuíam mestrado nas seguintes áreas: Enfermagem, Saúde Pública; e Ambiente e Saúde. Apenas uma enfermeira do estudo não apresentava especialização, os demais se especializaram nas seguintes áreas de conhecimento: Gestão hospitalar; Gestão universitária; Urgência e emergência; Centro cirúrgico, central de material e esterilização e recuperação pós-anestésica; Segurança do paciente; Estomaterapia; Reabilitação; e Neurologia.

Os cinco casos mostraram-se homogêneos, provavelmente pelos critérios de seleção adotados neste estudo, tornando possível observar diversas similaridades na fala dos participantes e nas observações realizadas nos CER. Foi comum os participantes relatarem as angústias de trabalhar com o distanciamento social, assim como a verbalização das formas que encontraram para reinventar o seu papel. Entretanto, houve enfermeiros que foram redirecionados para outras instituições de saúde, enquanto outros permaneceram no CER realizando ações de reabilitação à distância.

\section{Categoria 1: O choque de uma crise mundial - chegou} na nossa realidade

A pandemia por COVID-19, declarada em 30 de janeiro de 2020 pela Organização Mundial da Saúde (OMS), provocou mudanças do campo da saúde global. No contexto brasileiro, pode-se perceber mudanças políticas e sociais a partir de meados de Março de 2020, quando os casos confirmados da COVID-19 já haviam ultrapassado 214 mil em todo o mundo e ainda eram insuficientes os conhecimentos e planos estratégicos para conter a situação(10). Esse fato é percebido pelos participantes dos estudos ao mencionarem que em meados de 10 a 14 de março havia conversas, ainda tímidas, de uma crise de saúde e possível paralisação. Isso se estabeleceu como fato, a partir do Decreto $n^{\circ}$
562 de 17 de março de 2020, onde o estado de Santa Catarina, assim como muitos outros estados do Brasil, declarou situação de emergência e suspendeu as atividades dos CERs ${ }^{(11)}$.

“Eram conversas de corredor, mas já era sabido que existia um diagnóstico de crise, e que isso iria atingir o nosso serviço de alguma maneira". (Enf 01)

Diante da possibilidade de fechamento que se aproximava, muitos CERs se prepararam com pouca antecedência para a paralisação. Os enfermeiros de reabilitação surgiram como importante força para organizar os agendamentos, cancelamentos, orientações aos clientes de grupo de risco, informar sobre a COVID-19, cumprir acolhimentos de pacientes agendados, realizar reuniões de equipe e debater incertezas de tudo que ainda estaria por vir. Foram informados, ainda, os gestores do sistema de regulação e encaminhamento de novos pacientes sobre 0 cancelamento de agenda, informando a situação de paralisação.

"No dia 16 de março a nossa coordenação nos chamou para uma reunião, avisando que provavelmente as nossas atividades seriam suspensas. Diante disso, a gente organizou a nossa agenda de triagens e iniciou a busca ativa de todos os pacientes agendados para informar a interrupção do processo de reabilitação". (Enf 02)

“Essa paralisação foi necessária devido o cenário de pandemia e os usuários do CER pertencerem, em sua maioria, ao grupo de risco para a COVID-19". (Enf 03)

0 que se percebe na fala dos participantes é que o enfermeiro de reabilitação apresentou importante papel na gestão das agendas e cancelamentos, pois esse profissional realizou contatos telefônicos e orientou sobre situação da COVID-19 no estado, bem como informou mais profundamente os sujeitos que faziam parte de grupos de risco, direcionando condutas de prevenção e isolamento. Diante do cenário instalado, muitas incertezas emergiram sobre como exerceriam o cuidado nessa nova dinâmica de trabalho, além de importantes desdobramentos negativos associados aos impactos psicológicos e ressonância em diferentes setores da sociedade.

"Não sabíamos o que estaria por vir e nem quanto tempo ficaríamos afastados do cuidado presencial. Tudo isso era muito estressante. Saber que pessoas em processo de reabilitação ficariam estagnadas e a gente não pode fazer nada, isso é muito frustrante”. (Enf 03)

"Quando paramos tínhamos a previsão de retomar as atividades no dia 17 de abril, organizamos nossos esforços para isso, mas o que aconteceu foi o contrário, pois como você pode perceber já estamos indo para o terceiro mês de CER fechado". (Enf 02)

Diante ao cenário pessimista de estagnação, começaram-se a lançar datas que poderiam retornar as atividades, imaginando que a situação mundial melhoraria com rapidez e, mesmo com restrições, poderiam ser retomadas as atividades no CER o mais breve possível. Porém, essas falsas esperanças foram abandonadas a partir de um forte movimento mundial e nacional para as pessoas permanecerem em casa. Essa 
orientação de distanciamento e o isolamento social como estratégias para a sobrevivência à pandemia e desafogar os sistemas públicos e privados de saúde visava favorecer os sistemas de gestão e evitar o colapso. Esse cenário inédito na vivência contemporânea prendeu as pessoas em suas casas, permitindo somente vislumbrar o mundo pelas suas janelas.

Categoria 2: 0 enfrentamento da pandemia com as portas fechadas

Diferentemente da categoria anterior, onde percebe-se a maior similaridade nos relatos sobre do processo de encerramento dos serviços em meados de 18 de março de 2020, nessa próxima categoria aprofundam-se discussões sobre as diversidades encontradas nos enfrentamentos de cada CER, considerando que as diferenças advêm de questões políticas e institucionais que regem o serviço, impactando diretamente no cuidado de enfermagem de reabilitação. Dessa maneira, os dados são subdivididos em dois casos específicos onde agregam as diferenças e semelhanças entre cada realidade dos enfermeiros de reabilitação.

\section{Subcategoria: Caso 1 - CER de Florianópolis e Criciúma}

O CER de Florianópolis, intitulado Centro Catarinense de Reabilitação (CCR), apresenta sua área de abrangência na macrorregião da capital do estado de Santa Catarina, envolvendo 22 municípios. Nessa instituição existem onze enfermeiras lotadas, sendo oito na área administrativa e três assistenciais. Já o CER de Criciúma é vinculado a Universidade do Extremo Sul Catarinense (UNESC), amparando a região carbonífera do estado catarinense, a qual compreende 28 municípios e apresenta apenas uma enfermeira na área assistencial $^{(5)}$.

Esses dois casos foram associados no corpo deste artigo por apresentarem a similaridade de ambas as instituições realocaram os profissionais para setores assistenciais. No caso do CCR todos os profissionais foram direcionados para dois hospitais de referência do município: Hospital Nereu Ramos e Hospital Infantil Joana de Gusmão; enquanto o CER de Criciúma apenas realocou alguns profissionais: a enfermeira para a Clínica Integrada, o fisioterapeuta para atividades administrativas e os psicólogos para o projeto Acolher.

"O CCR parou e no dia 24 de março, todos os profissionais foram realocados. Todos! Enfermeiros, fisioterapeutas, médicos... Foi metade pro Nereu e metade pro Infantil, e lá estavam até pouco tempo". (Enf 04)

"Eu passei a trabalhar na vacinação de Influenza na Clínica Integrada da universidade. Nesse contexto vacinamos as pessoas conforme as normas do Ministério da Saúde, atendendo em formato de Drive-Thru e ambulatório. Uma fisioterapeuta passou a realizar atividades administrativas e psicólogos passaram a acolher questões de saúde mental de outros colaboradores da instituição". (Enf 05)
No caso do CCR, os profissionais exerceram ações de cuidado em unidades de clínica médica, terapia intensiva e clínica cirúrgica. Já a enfermeira do CER de Criciúma refere que participou do processo de vacinação, bem como o desenvolvimento de materiais digitais, como por exemplo E-book relacionados à temática de cuidados com a pele e estomaterapia.

"Eu fiquei no Nereu, trabalhei na área feminina e na unidade de tuberculose. Fiquei nas duas! Foi uma experiência muito legal porque fazia tempo que não entrava num hospital. A equipe nos acolheu muito bem". (Enf 04)

"Desenvolvi um E-book sobre estomaterapia, Lives sobre orientações de cuidados domiciliares $e$ Workshops de temáticas diversas, conforme a necessidade dos nossos usuários". (Enf 05)

Um diferencial do CCR, é que a enfermeira e sua chefia direta da unidade de OPME, retornaram às atividades na primeira semana de maio. Desde então, enquanto os profissionais exercem seus papéis intra-hospitalar, a enfermeira realiza ações gerenciais acerca da agenda de consultas e ingressos no processo de reabilitação, bem como liberar materiais, equipamentos de órteses e próteses, e itens com data de vencimentos próximo. Os agendamentos exigem a interlocução entre a enfermeira, o sistema de regulação do SUS e pessoas em reabilitação. Essas ações vislumbram o retorno das atividades assistenciais previstas para o dia oito de junho de 2020.

"Comecei a reorganizar a agenda desses três meses: março, abril e maio. Reagendar as consultas e ingressos pelo sistema de regulação e informar os pacientes [...] $\mathrm{Na}$ OPME, unidade onde eu trabalho, voltamos na primeira semana de maio porque tínhamos muitos equipamentos e materiais que necessitavam ser liberados e outras questões administrativas. Além disso começamos o cronograma para retomar as atividades a partir do dia 08 de junho [...] Para retomar as atividades, foi elaborado um protocolo rígido que segue orientações internacionais, considerando: redução de aglomeração, redução no número de atendimentos, higienização do ambiente na troca de pacientes, triagem inicial para todos os pacientes pela equipe de enfermagem, apenas um acompanhante $e$ uso adequado de equipamentos de segurança individual". (Enf 04)

Já o CER de Criciúma optou por medidas virtuais uso de redes sociais para abordar temáticas multiprofissionais e aproximar o serviço dos paciente e famílias. Outra iniciativa foi através do projeto Acolher, onde psicólogos desenvolveram ações de saúde mental para profissionais na linha de frente contra a COVID-19, bem como atender os colaboradores com práticas integrativas e complementares. Essas condutas permearam aproximadamente 2 meses, até dia primeiro de junho de 2020, quando retomaram as atividades presenciais.

"Esses remanejamentos geravam muitos desafios de adaptação, mas também muita reflexão sobre amparar os pacientes. Isso me deixou bastante desconfortável, gerando um desequilíbrio emocional comigo. Sou enfermeira e isso mexeu bastante comigo. Mas penso 
que as orientações no momento das vacinas me ajudaram a suprir essa questão [...] Tivemos muita melhora no cenário quando começamos as práticas integrativas. Além disso tem os Workshops e Lives para disseminar conhecimentos e orientações. Faço parte disso tudo, práticas integrativas, vacinação, buscaativa de como os pacientes estão, orientação on-line, grupos virtuais para acompanhamentos". (Enf 05)

Ambas instituições retomaram as atividades presenciais e experimentam diariamente a necessidade de elaborar protocolos que englobam as restrições e segurança no serviço, visando a higiene do ambiente e prevenção de contaminação. Essas medidas apresentam-se em processo construtivo no momento da coleta de dados, mas ambas as enfermeiras reforçam que essas diretrizes consideraram normas internacionais e medidas preconizadas pelo Ministério da Saúde no Brasil.

\section{Subcategoria: Caso 2 - CER de Lages e Blumenau}

O CER de Lages, vinculado à Universidade do Planalto Catarinense (UNIPLAC), apresenta sua área de abrangência na macrorregião da serra catarinense, envolvendo 18 municípios. Já o CER de Blumenau, vinculado à Universidade Regional de Blumenau (FURB), apresenta sua área de abrangência na macrorregião do Vale do Itajaí, envolvendo 14 municípios(5).

Entre esses CERs citados, existem três enfermeiros de reabilitação exercendo ações assistenciais, os quais seus trabalhos foram intensamente impactados. Após a determinação de fechamento dos serviços, ambas as instituições iniciaram atividades em Home Office, incluindo vídeo chamadas, teleconsulta, vídeo aulas e vídeos ao vivo em mídias sociais. Os atendimentos à distância priorizavam suprir as demandas familiares específicas para o desenvolvimento da pessoa em reabilitação no meio domiciliar.

"Sabendo da importância da reabilitação, a equipe do CER desenvolveu uma nova forma de atendimento: o Home Office". (Enf 03)

"A equipe multidisciplinar continua trabalhando em equipe para continuar prestando assistência de reabilitação aos nossos pacientes através de ligações telefônicas, mensagens de Whatsapp, mensagens de voz e conferências por vídeo. Não existindo quaisquer atendimentos presenciais em todo esse período". (Enf 02)

A partir de diagnósticos de enfermagem, relatos familiares, questões sociais, recursos tecnológicos e de ambiência, assim como as metas estabelecidas no Projeto Terapêutico Singular (PTS), a equipe multidisciplinar elaborou abordagens terapêuticas em formato de atividades dinâmicas guiadas à distância e acompanhadas por feedbacks dos pacientes por meio de mídias digitais. Nesse processo de levantamento de necessidades individuais e coletivas, os enfermeiros relataram importante ação no fortalecimento de vínculo e estratificação de dados. Além disso, as teleconsultas serviram como um mecanismo de avaliação, intervenção e controle de enfermagem relacionadas, principalmente, à terapia medicamentosa, queixas físicas ou psíquicas, integridade da pele, hábitos alimentares, atividades físicas, lazer, rotina diária e qualidade do sono.

"Os usuários nos procuram para falar sobre medicamentos, como conseguir receita, onde e como faz para conseguir a vacina da Influenza, quais os pontos da atenção primária de referência para o atendimento" (Enf 02)

"A enfermagem do CER foi e é peça fundamental no planejamento e organização das escalas e atividades que estão acontecendo em Home Office. A partir do diagnóstico dos enfermeiros sobre as famílias, demanda social, disponibilidade e objetivos da reabilitação, traçou junto com a equipe as estratégias de planejamento a fim de atingirmos o máximo de usuários com eficácia”. (Enf 01)

"Fizemos levantamento de características de cada família, disponibilidade de tecnologias, tempo e recursos para planejarmos a melhor forma de intervenção junto com a equipe, levando em consideração o PTS inicial $e$ os objetivos da reabilitação”. (Enf 03)

Dentre as atividades realizadas pela equipe de enfermagem, o uso de mídias sociais surgiu como uma ferramenta para compartilhar conhecimentos e disseminar atividades domiciliares que agregassem qualidade de vida em tempos de pandemia. As temáticas principais abordadas nesse veículo de orientação envolveram questões relacionadas às medidas de prevenção de COVID-19 na vivência cotidiana, motivações e saúde mental, reabilitação vesico-intestinal, uso adequado de máscara de tecido e higienização da mesma, além do fortalecimento de medidas de isolamento. Outro aspeto importante do uso das mídias sociais relaciona-se à possibilidade de acompanhamento diário e semanal do desenvolvimento das famílias ao convívio intrínseco do processo de reabilitação através de vídeos, mensagens e áudios, valorizando o engajamento e avaliando clinicamente a melhora terapêutica individual.

"Os atendimentos passaram a acontecer via Whatsapp e ligação telefônica, enviando propostas de atividades, por exemplo, eles mandavam fotos de feridas e eu orientava como seguir com o curativo. Outro aspeto envolveu o enfrentamento da pandemia, visando motivar os pacientes a não desistirem dos exercícios propostos pela equipe e 'puxar' a orelha para que continuassem cuidando das comorbidades". (Enf 03)

"A enfermagem também constrói materiais didáticos para as redes sociais do CER, procurando temas importantes para os nossos pacientes. Buscamos usar esse veículo para orientar, mas também melhorar a saúde mental e fortalecer nosso vínculo com a família". (Enf 02)

"E ainda realizamos vídeos falando sobre como cuidar para não adquirir o COVID-19. A maioria dos nossos pacientes fazem parte do grupo de risco para Coronavírus, por isso, eu me esforcei para orientar eles quanto às medidas de prevenção". (Enf 01)

O enfermeiro de reabilitação assume, portanto, um papel imprescindível para a continuidade da reabilitação dos sujeitos e suas famílias, acrescentando 
esforços para manter o vínculo diário e reduzir as perdas funcionais com o distanciamento social. Nesse sentido, muitos obstáculos emergiram como dificultadores no cuidado desses enfermeiros, principalmente associados à fragilidade da profissão em necessitar do toque e presença para exercer seu trabalho. É evidente que foram modificadas as medidas de cuidado para otimizar a vivência domiciliar, porém esse processo foi permeado de ansiedade e fadiga em assistir as demandas dos pacientes à distância. Por outro lado, a ligação que as redes sociais criaram evidenciou uma nova forma de estabelecer relações de confiança, onde a responsabilização do processo terapêutico é fortemente transferida à participação familiar.

"No princípio eu pensei: Como fazer reabilitação em Home Office? Era frustrante imaginar que nossos pacientes estariam desassistidos e perdendo qualidade de vida. Esse processo todo está sendo muito cansativo, parece que trabalhamos mais do que pessoalmente. Penso que essa sensação surge da obrigação em fazer diferente e correr contra o tempo para evitar perda funcional". (Enf 03)

"É muito pesado carregar a culpa de não poder estar junto com a família nessa situação toda e se esforçar para que esse processo não seja tão doloroso. Quando começamos os atendimentos à distância esperávamos pouca adesão da família, mas estávamos enganados. É grandiosa a surpresa do engajamento familiar". (Enf 02)

"Todas as vezes que falamos para o paciente e familiares que eles eram o centro do cuidado e que eles tinham que entender a responsabilidade deles na reabilitação, agora tornou-se mais evidente. A família entendeu que a reabilitação é muito importante, e buscou alicerce nas nossas orientações para fazer em casa”. (Enf 01)

Mesmo diante às similaridades dos relatos dos enfermeiros de reabilitação acerca da situação vivenciada, cada instituição apresenta-se em momentos diferentes no final. O CER de Blumenau, por exemplo, mantém as ações de cuidado à distância conforme mencionado, enquanto o CER de Lages estagnou suas atividades em sete de maio de 2020. Essa paralisação das atividades do CER de Lages advém de uma decisão institucional em cessar as atividades da universidade vinculada. 0 enfermeiro desse CER relata que foi elaborado um questionário On-line para os pacientes responderem sobre o interesse em retomar as atividades, averiguando sinais ou sintomas de COVID19. Além disso, esse enfermeiro elaborou um protocolo de ações para potencializar a segurança no retorno das atividades, considerando medidas de higiene $e$ aglomeração, mas essas condutas foram ineficazes, inexistindo contato presencial ou à distância com usuários e famílias desde então.

"Estou muito preocupado se as pessoas ainda estão seguindo nossas orientações, se ainda estão realizando atividades, se a família está participando desse processo. A gente se sente frustrado e de 'mãos amarradas', porque não podemos fazer nada. É angustiante não saber se estão seguindo orientações de dieta, prescrições medicamentosas, cuidados com a pele. É complicado". (Enf 03)

\section{Categoria 3: 0 que será do futuro?}

Como será o cuidado de enfermagem após a pandemia? Como viveremos em coletividade após tanto isolamento social? Existirão impactos longitudinais na reabilitação após esse processo de distanciamento? Essas são interrogações que emergem, intrinsecamente, do processo que estamos vivenciando na atualidade, por isso a terceira, e última, categoria evoca os sentimentos compartilhados por todos os enfermeiros acerca dos horizontes ainda incertos da vida após pandemia.

É fato que a pandemia está causando desastres sem precedentes em relação à saúde, sociedade e economia em nível mundial, porém ainda é cedo para prever qualquer cenário realista. Mesmo assim, as esperanças do futuro surgem através de medidas de prevenção e manejo adequado do presente, consistindo no uso de máscaras faciais; na higiene das mãos regularmente; evitar o contato com pessoas infetadas; manter uma distância adequada das pessoas; e abster-se de tocar olhos, nariz e boca com as mãos ${ }^{(12)}$.

Diante dessa perspetiva, toda a amostra apresentou semelhança ao expor seus anseios sobre o futuro que circunda o cuidado que prestam na atualidade. Agregam valor às orientações da OMS e Ministério da Saúde do Brasil, mencionam medidas de precaução e criam esperanças de um retorno gradual dos atendimentos. Porém, evidenciam-se, nos dados citados no corpo deste estudo, que a tomada de decisão sobre o retorno ainda é diversificada, ao passo que há movimentos para o retorno das atividades pelo CER de Florianópolis, enquanto o CER de Lages tem expectativas para o mês de julho e o CER de Blumenau não apresenta previsões.

"Todos estamos muito ansiosos com tudo isso. Retomamos as atividades e já nos angustia a sensação de ter uma fila de atendimentos pendentes. Além disso, pensando na pessoa em reabilitação e sua família, os impactos da interrupção do serviço gera repercussões na qualidade de vida em dimensões imensuráveis. Outra questão é a obrigatoriedade de avaliação do paciente antes de qualquer procedimento pela equipe de enfermagem. Esse novo cenário gera fadiga diante tantas mudanças diárias de condutas". (Enf 04)

"Acredito que a Pandemia está fazendo e fará ainda com que a enfermagem reflita sobre suas práticas principalmente no alcance de objetivos sociais que antes não ficavam muito evidentes. A Pandemia também nos trouxe uma reflexão acerca da possibilidade de inserção do cuidado a distância, das práticas de reabilitação com acompanhamento $e$ orientação sem o contato físico e de que a ausência deste contato físico não torna a prática menos eficaz, pois é possível um cuidado de qualidade no conforto do lar. O cenário pós pandemia talvez traga para a reabilitação outras perspetivas, como a inserção da reabilitação psicossocial como evidência". (Enf 01) 
“Estávamos muito ansiosos para o retorno porque a distância nos abalou muito psicologicamente, $e$ ao mesmo tempo com muita carência acerca do cenário de cuidado que tanto prezamos". (Enf 05)

Diante a atual conjuntura, torna-se fundamental desenhar o sistema de saúde de forma a potenciar as competências e intervenções de cada profissional, com o objetivo de tratar pessoas com COVID-19, de prevenir contágio de COVID-19 sobretudo a pessoas vulneráveis e prevenir complicações associadas à doença. Logo, os cuidados do enfermeiro de reabilitação voltam-se para a capacitação do sujeito e sua família sobre a autogestão do regime medicamentoso, dieta e exercícios domiciliares, bem como técnicas específicas para melhorar os sintomas de dispneia, aliviar a ansiedade e a depressão, reduzir as complicações, prevenir e melhorar a disfunção respiratória, reduzir a incapacidade e melhorar a qualidade de vida ${ }^{(13)}$.

"Acredito que no retorno terá que ser intensificado o monitoramento de sinais vitais e medidas de higiene, até porque o vírus vai se manter na sociedade. Por isso, o segredo é manter os cuidados continuamente [...] Além disso, tudo é muito inseguro, tudo é incerto ainda na verdade. Até que tudo se ajeite, o cuidado será pela escuta e comunicação". (Enf 03)

Dentre as ações de cuidados recomendadas na literatura que corroboram aos achados desse estudo, há a valorização da continuidade dos cuidados de enfermagem de reabilitação de acordo com a tolerância da pessoa e o reforço das precauções universais de controle de infeção. Ainda é validado na literatura que o contato telefônico e o uso de novas tecnologias para follow-up e esclarecimento de dúvidas têm possibilitado ao enfermeiro assumir privilegiado enquanto educador. Bem como, esse profissional assume papel importante na diminuição da ansiedade provocada pela doença, promovendo a sua autonomia, e identificação precoce de sintomas respiratórios para a rápida intervenção(14).

Ressalta-se ainda que o enfermeiro de reabilitação assume posição de mobilizador de dados determinantes para estratégias de ações que promovam a participação na em planos de contingências, garantido equipamentos de proteção, medidas de higiene e segurança, identificação precoce de sinais de agudização respiratória e dar continuidade ao processo de reabilitação mesmo com o distanciamento social, evitando assim perda de funcionalidade e autonomia ${ }^{(6 ;}$ 15). Logo, pode-se não saber o que será do futuro, porém é reconhecido o valor desse profissional como mediador da melhor qualidade de vida ${ }^{(15)}$.

\section{CONCLUSÃO}

Conclui-se que são diversas as experiências dos enfermeiros de reabilitação mesmo diante da similaridade da amostra e recorte da pesquisa. A pandemia impactou diretamente o processo de trabalho dos enfermeiros, realizando atendimentos à distância ou atividades intra-hospitalares. Dessa forma, o distanciamento social refletiu como fator impedidor do trabalho desses enfermeiros, gerando frustrações e anseios quanto ao cuidado de reabilitação, mas também valorizando seu papel como fomentador de confiança e vínculo. Essa pesquisa possibilitou reconhecer como a enfermagem de reabilitação têm elaborado medidas de cuidado e as práticas que modificaram diante do cenário de pandemia, fomentando a valorização da especialidade no contexto brasileiro e preenchendo as lacunas na incipiência literária sobre a temática.

\section{REFERÊNCIAS BIBLIOGRÁFICAS}

1. Silva CS, Martins MMFPS, Pereira RSS, Pacheco MN, Carvalho AE, Machado WCA. Acessibilidade dos edifícios destinados à prática de desporto nas pessoas com deficiência: Intervenção dos/as enfermeiros/as especialistas em reabilitação. Rev Port Enferm Reabil [Internet]. 2019; 2(2) 27-32. Available from: https://www.aper.pt/ficheiros/revista/RPERv2n2.pdf

2. Mancussi AC. Enfermagem em reabilitação: ampliando os horizontes, legitimando o saber. Rev Esc Enferm USP [Em linha]. 2006;40(1):128-33. [Consult. 02-03-2019]. Disponível na internet: ISSN 0080-6234.

3. Schoeller SD, et al. Breve panorama mundial da enfermagem de reabilitação. Rev Port Enferm Reabil [Internet]. 2018 [cited 2020 Jun 1];1:6-13. Available from: https://www.aper.pt/ficheiros/revista/rperv1n1.pdf

4. Brasil MS. Saúde da Pessoa com Deficiência: diretrizes, políticas e ações [Internet]. Ministério da Saúde. 2013. Available from: http: / /www.saude.gov.br/saude-de-a-z/saude-da-pessoa-comdeficiencia

5. Saúde SE. Serviços de Reabilitação: Santa Catarina [Internet]. Governo no estado de Santa Catarina. 2019. Disponível em: http://www.saude.sc.gov.br/index.php/resultadobusca/geral/10259-rede-de-cuidados-a-pessoa-com-deficiencia. Acesso em: 02 jun. 2020.

6. Areosa SVC., Gaedkeo MA. A pandemia da COVID-19, o isolamento social e as revistas científicas. J Infect Control [Internet]. 2020 May 03 [cited 2020 May 27];Cartas ao editor: 1-2.Available from: http://www.jicabih.com.br/index.php/jic/article/view/299/pdf

7. Andrade SR, Ruoff AB, Piccoli T, Schmitt MD, Ferreira A, Xavier ACA. $O$ estudo de caso como método de pesquisa em enfermagem: uma revisão integrativa. Texto contexto - enferm. [Internet]. 2017 [citado 2020 Jun 01]; 26(4):e5360016. Disponível em: http: //www.scielo.br/scielo.php?script=sci_arttext\&pid=S0104$07072017000400308 \&$ ing $=p t$.

8. Gautério-Abreu AP, Ávila JA, Santos SSC, Itha S, Silva BT. Contribuições do estudo de caso para o cuidado de enfermagem: um relato de experiência. Rev enferm UFPE [online]. 2016; $10(3): 1149-54$.

em: Disponível SM. 1003201627

9. Bardin L. Análise de conteúdo. São Paulo: Edições 70, 2011, 229 p.

10. World Health Organization. Director-Gener - al's statement on IHR Emergency Committee on Novel Coronavirus (2019-nCoV), Gene - bra, $2020 . \quad$ Available from: https://www.who.int/dg/speeches/detail/who-directorgeneral-s-statement-onihr-emergency-committee-on-novelcoronavirus-(2019-ncov)

11. Saúde SE. Decreto $n^{\circ} 562$, de 17 de abril de 2020 [Internet]. Governo no estado de Santa Catarina. 2020. Disponível em: http://www.saude.sc.gov.br/coronavirus/arquivos/decreto_562 .pdf

12. Schmidt B, Crepaldi MA, Bolze SDA, Neiva-Silva L, Demenech LM. Impactos na Saúde Mental e Intervenções Psicológicas Diante da Pandemia do Novo Coronavírus (COVID-19). SciELO Preprints [Internet]. 2020; 1(1) 01-26. Available from: https://preprints.scielo.org/index.php/scielo/preprint/view/58 169

13. Couto ES, Couto ES, Cruz IMP. Fique em casa: educação na pandemia da COVID-19. Interfaces Científicas - Fluxo Contínuo [Internet]. 2020; 8(3) 200-217. Disponível em: https://periodicos.set.edu.br/index.php/educacao/article/view $/ 8777$

14. Gennaro FD et al. Coronavirus Diseases (COVID-19) Current Status and Future Perspectives: A Narrative Review. Int. J. Environ. Res. 
Public Health. 2020; 17(2690): 1-11. Available from: https://www.ncbi.nlm.nih.gov/pmc/articles/PMC7215977/pdf/i jerph-17-02690.pdf

15. Rocha BMP. O papel do enfermeiro de reabilitação e a pandemia COVID-19. Ordem dos Enfermeiros - Mesa do colégio da especialidade de enfermagem de reabilitação [Internet]. 2020; 1 . $7 . \quad$ Disponível em: https: / /www.aper.pt/Ficheiros/Covid19/0\%20PAPEL\%20DO\%20E NFERMEIRO\%20DE\%2OREABILITA\%C3\%87\%C3\%830\%20E\%20A\%20PA NDEMIA\%20COVID-19.pdf 